\title{
Effect of phlorotannins on myofibroblast differentiation and ECM protein expression in transforming growth factor $\beta 1$-induced nasal polyp-derived fibroblasts
}

\author{
JUNGIK PARK $^{1 *}$, GRACE CHOI ${ }^{2 *}$, MI-JIN YIM ${ }^{2}$, JEONG MIN LEE ${ }^{2}$, JONG SU YOO $^{2}$, WON SUN PARK ${ }^{3}$, \\ SEONG KOOK PARK ${ }^{4}$, SAEGWANG PARK $^{5}$, SU-KIL SEO ${ }^{5}$, TAE-GEUM KIM ${ }^{6}$, \\ DAE-SUNG LEE ${ }^{2}$ and IL-WHAN CHOI ${ }^{5}$
}

\begin{abstract}
${ }^{1}$ Division of Endocrinology and Metabolism, Department of Internal Medicine, Dong-Eui Medical Center, Dong-Eui University, Busan 47227; ${ }^{2}$ Department of Applied Research, National Marine Biodiversity Institute of Korea, Seocheon, Chungcheongnam-do 33662; ${ }^{3}$ Department of Physiology, Kangwon National University School of Medicine, Chuncheon, Gangwon-do 24341; ${ }^{4}$ Department of Otorhinolaryngology Head and Neck Surgery, Busan Paik Hospital;

${ }^{5}$ Department of Microbiology and Immunology, College of Medicine, Inje University, Busan 47392;

${ }^{6}$ Center for Jeongup Industry-Academy-Institute Cooperation, Chonbuk National University, Jeonju, Jeollabuk-do 54896, Republic of Korea
\end{abstract}

Received January 25, 2018; Accepted July 6, 2018

DOI: $10.3892 /$ ijmm.2018.3770

\begin{abstract}
Phlorotannins (PTNs), a group of phenolic compounds from seaweeds, have diverse bioactivities. However, there has been no report on their antifibrotic effects during nasal polyp (NP) formation. In the present study, the effect of PTNs on transforming growth factor (TGF)- $\beta 1$-induced profibrotic responses in nasal polyp-derived fibroblasts (NPDFs) were determined and the relevant signaling pathways were investigated. The expression levels of collagen type-1 (Col-1) and fibronectin in NP tissues were measured by western blot analysis and immunohistochemistry. The NPDFs were treated with TGF- $\beta 1(1 \mathrm{ng} / \mathrm{ml})$ in the presence or absence of PTNs $(5-30 \mu \mathrm{g} / \mathrm{ml})$. The expression levels of $\alpha$-smooth muscle actin ( $\alpha$-SMA), Col-1, fibronectin, and phosphorylated-small mothers against decapentaplegic (Smad)2/3 in NPDFs were measured by western blot analysis. The contractile activity of the NPDFs
\end{abstract}

Correspondence to: Professor Il-Whan Choi, Department of Microbiology and Immunology, College of Medicine, Inje University, 75 Bokji-Ro, Busanjin-gu, Busan 47392, Republic of Korea E-mail: cihima@inje.ac.kr

Dr Dae-Sung Lee, Department of Applied Research, National Marine Biodiversity Institute of Korea, 75 Jangsan-ro, Janghang-eup, Seocheon, Chungcheongnam-do 33662, Republic of Korea

E-mail: daesung@mabik.re.kr

${ }^{*}$ Contributed equally

Key words: nasal polyps, phlorotannins, extracellular matrix, $\alpha$-smooth muscle actin, small mothers against decapentaplegic $2 / 3$ was determined by a collagen gel contraction assay. Col-1 and fibronectin proteins were found to be expressed in NP tissues. PTNs had no significant cytotoxic effect on TGF- $\beta 1$-induced NPDFs. TGF- $\beta 1$ induced the expression $\alpha$-SMA, Col- 1 and fibronectin, and stimulated fibroblast-mediated contraction of collagen gel. However, pre-treatment with PTNs inhibited the expression of these proteins. The inhibitory effects were mediated through the suppression of $\operatorname{Smad} 2 / 3$ signaling pathways in TGF- $\beta 1$-induced NPDFs. These resulted suggested that PTNs may be important in inhibiting myofibroblast differentiation and extracellular matrix protein accumulation in NP formation through the Smad2/3 signaling pathway.

\section{Introduction}

Nasal polyps (NPs) are pink-colored, tear-drop shaped outgrowths, which form either in the nose or in the paranasal sinuses. NPs are characterized by tissue remodeling, consisting of stromal and epithelial cell proliferation, inflammatory cell infiltration, goblet cell hyperplasia, pseudocyst formation, focal fibrosis, edema, and basement membrane thickening, with a high recurrence rate in the nose and paranasal sinuses $(1,2)$. The majority of individuals with NPs exhibit morbidities, including nasal congestion, rhinorrhea, decreased taste, anosmia and headaches, which reduce the individual's quality of life (3). NPs typically embody a chronic infiltration of inflammatory cells. The recurrence of NPs, following surgical procedure, is common; therefore, many patients require additional procedures. The etiology and pathophysiology of NPs formation remain to be fully elucidated. However, according to reports by other research groups, a remodeling process is considered to be involved; damage to the mucosal epithelium is accompanied by extracellular matrix (ECM) protein accumulation and inflammatory cell infiltration (4). 
Several types of cells, including epithelial cells, $\mathrm{T}$ cells, mast cells and fibroblasts, are involved in the pathogenesis of NPs (5). Among these, fibroblasts are the major structural components of NP architecture and are actively involved in NP formation (6). Fibroblasts are found in the stroma and are the cellular source of ECM components, including collagen and fibronectin, the excessive deposition of which is characteristic of the majority of fibrotic responses (7).

Marine algae have been traditionally used in folk medicine and as ingredients in food in Asian countries. Marine algae are rich sources of vitamins, minerals, dietary fibers, proteins, polyunsaturated fatty acids, essential amino acids and bioactive substances (8), which have antioxidant, anti-inflammatory, antiviral, anticoagulant, anticancer, immunomodulatory and antibacterial activities $(9,10)$. Marine algae also form a potential resource for bioactive secondary metabolites, which may provide useful leads for the development of pharmaceuticals $(11,12)$. Phlorotannins (PTNs), a group of hydrophilic phenolic compounds from marine algae, consist of polymers of phloroglucinol units with a wide range of molecular sizes (126-650 kDa) (13). PTNs have diverse bioactivities, including antioxidant, anti-inflammatory, antiviral, antitumor, antidiabetic and anticancer properties $(14,15)$. However, neither the antifibrotic activity nor the regulatory mechanism of PTNs in nasal polyp-derived fibroblasts (NPDFs) have been reported previously.

The present study investigated the effect of PTNs on TGF- $\beta$-induced myofibroblast differentiation and expression of profibrotic proteins, including collagen type-1 (Col-1) and fibronectin, in NPDFs, which mimic the conditions of NP formation. The potential regulatory mechanism of PTNs on the expression of profibrotic factors was also examined.

\section{Materials and methods}

Reagents. The PTNs were provided by Professor W. K. Jung (Pukyong National University, Busan, Korea). TGF- $\beta 1$ was purchased from R\&D Systems, Inc. (Minneapolis, MN, USA). The Cell Counting Kit-8 (CCK-8) was purchased from Dojindo Molecular Technologies, Inc. (Kumamoto, Japan). Antibodies against $\alpha$-smooth muscle actin ( $\alpha$-SMA; cat no. ab5694) and Col-1 (cat. no. ab88147) were purchased from Abcam (Cambridge, MA, USA). Antibodies against actin (cat. no. 612656) and fibronectin (cat. no. 610077) were purchased from BD Biosciences (San Jose, CA, USA). Antibodies against goat anti-mouse IgG-horseradish peroxidase (HRP) conjugate (cat. no. LF-SA8001) and GAPDH (cat. no. LF-PA0018) were purchased from Young In Frontier Co., Ltd. (Seoul, Korea). Antibodies against phosphorylated (p-) small mothers against decapentaplegic (Smad)2 (cat. no. 3101) and p-Smad3 (cat. no. 9520) were purchased from Cell Signaling Technology, Inc. (Danvers, MA, USA). Smad2/3-specific small interfering (si)RNAs (cat. no. sc-37238) were purchased from Santa Cruz Biotechnology, Inc. (Santa Cruz, CA, USA). Rat tail type-1 collagen was purchased from BD Biosciences.

NP-derived fibroblast culture. Patients with NPs were recruited and NPDFs were cultured as in our previous report (16). Individuals were diagnosed with NPs based on the minimal criteria for chronic rhinosinusitis with NPs. A total of 15 subjects (male:female, 9:6; median age, 43) with NPs and 15 subjects with deviated nasal septa were recruited from the Department of Otorhinolaryngology, Inje University Pusan Paik Hospital (Pusan, Korea) between July 2017 and September 2017. Written informed consent was obtained from each patient and the study was approved by the Ethics Committees of Inje University Pusan Paik Hospital (Pusan, Korea). A NP was defined as the presence of endoscopically visible bilateral polyps growing from the middle nasal meatus into the nasal cavities, and affecting the ethmoid and maxillary sinuses on computed tomography (CT) of the paranasal sinus. NPs were obtained from the region of the middle meatus at the beginning of the surgical procedure. As a control, nasal mucosal tissue was also obtained from the inferior turbinate (IT) of patients who underwent a septoturbinoplasty. The subjects had no history of nasal allergy, asthma, or aspirin sensitivity. The diagnosis of allergy was based on both a history of allergy and the results of ImmunoCAP or skin prick tests. No patient had received steroids (systemic or topical), nonsteroidal anti-inflammatory drugs, antihistamines, or macrolide antibiotics during the 4 weeks before the biopsy. NPDFs were isolated from surgical tissues by enzymatic digestion with collagenase $(500 \mathrm{U} / \mathrm{ml}$; Sigma-Aldrich; Merck KGaA, Darmstadt, Germany), hyaluronidase (30 U/ml; Sigma-Aldrich; Merck KGaA), and DNase (10 U/ml; Sigma-Aldrich; Merck KGaA). Cells were cultured in Dulbecco's Modified Eagle Medium (DMEM) containing 10\% (v/v) heat-inactivated fetal bovine serum (Invitrogen; Thermo Fisher Scientific, Inc., Waltham, MA, USA), 1,000 U/ml penicillin, and 1,000 $\mu \mathrm{g} / \mathrm{ml}$ streptomycin (Invitrogen; Thermo Fisher Scientific, Inc.) at $37^{\circ} \mathrm{C}$ in an atmosphere containing $5 \% \mathrm{CO}_{2}$. The purity of the NPDFs was confirmed by flow cytometry and characteristic spindle-shaped cell morphology. Experimental cells were used in the fourth to six cell passages.

Immunohistochemistry. To detect Col-1 and fibronectin, immunohistochemistry was performed as previously reported (16). Briefly, 5- $\mu \mathrm{m}$-thick NP sections were prepared from formalin-fixed paraffin-embedded tissues. The sections were incubated overnight with Col-1 (1:100) and fibronectin (1:300) antibodies at $4^{\circ} \mathrm{C}$ overnight. The slides were then incubated with anti-mouse IgG-HRP at a 1:2,000 dilution for $1 \mathrm{~h}$ at room temperature in the dark. DAB was used as a chromogen, and Mayer's hematoxylin was used for counterstaining. The expression levels of Col-1 and fibronectin were evaluated under a digital slide scanner (NanoZoomer 2.0-RS; Hamamatsu, Shizuoka, Japan).

Cell viability assay. Cellular viability was assessed using the CCK-8 (Dojindo Molecular Technologies, Inc.). In a 96-well microplate, NPDFs $\left(1 \times 10^{5}\right.$ cells/well) were treated with PTNs $(5,10$ and $30 \mu \mathrm{M})$. Following incubation for $24 \mathrm{~h}$ at $37^{\circ} \mathrm{C}$ in an atmosphere of $5 \% \mathrm{CO}_{2}$, the cells were washed twice with PBS. CCK-8 solution was then added to each well and incubated at $37^{\circ} \mathrm{C}$ for $1 \mathrm{~h}$, followed by an absorbance analysis at $450 \mathrm{~nm}$ using a microplate reader (SpectraMax M2e; Molecular Devices LLC, Sunnyvale, CA, USA). All assays were performed in triplicate.

Western blot analysis. The cells were lysed with lysis buffer (Mammalian Cell-PE LB; G-Biosciences, St. Louis, MO, USA). Protein concentration was quantified using the 

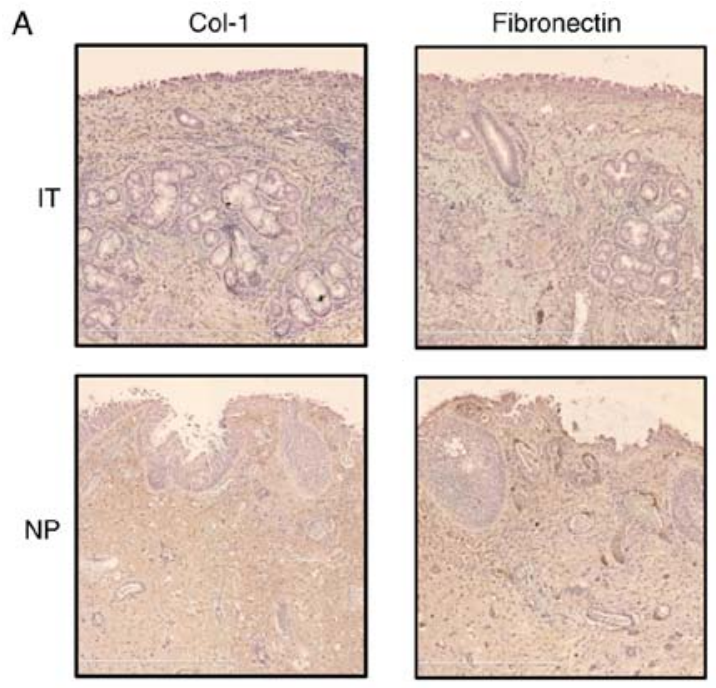

B

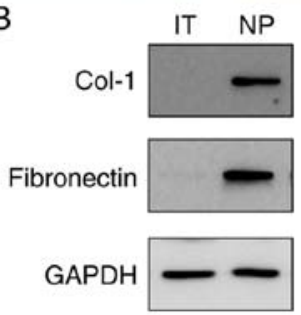

Figure 1. Expression of Col-1 and fibronectin in NP tissues. (A) Distribution of Col-1 and fibronectin in samples of NP tissues was examined by immunohistochemical staining using anti-Col-1 and anti-fibronectin antibodies. Magnification, x20. (B) Western blot analysis of NPs. IT, inferior turbinate tissue; NP, nasal polyp; Col-1; collagen type-1.

Bradford method (Bio-Rad protein assay dye reagent concentration; Bio-Rad Laboratories, Inc., Hercules, CA, USA). Equal quantities of protein $(20 \mathrm{mg})$ were separated on $10 \%$ SDS-polyacrylamide mini-gels and transferred onto nitrocellulose membranes (GE Healthcare Life Sciences, Chalfont, UK). Membranes were blocked in 5\% non-fat milk diluted in Tris-buffered saline $/ 0.1 \%$ Tween-20 (TBST) at room temperature for $1 \mathrm{~h}$. Following incubation with the appropriate primary antibody (a-SMA, Col-1, fibronectin, p-Smad2 and p-Smad3) at a dilution of 1:1,000 overnight at $4^{\circ} \mathrm{C}$, the membranes were incubated for $1 \mathrm{~h}$ at room temperature with secondary antibody conjugated to HRP (goat anti-mouse IgG; 1:1,000). Following three washes with TBST, the immunoreactive bands were visualized using an ECL detection system (Pierce; Thermo Fisher Scientific, Inc., Waltham, MA, USA) and band intensities were evaluated quantitatively using the Multi gauge version 2.2 software (Fuji Film, Tokyo, Japan).

Silencing of Smad2/3 by synthetic siRNAs. At $16 \mathrm{~h}$ following plating, the cells were transfected with Smad2/3-siRNAs (40, 80 and $100 \mathrm{nM})$ using the siRNA transfection reagent (Santa Cruz Biotechnology, Inc.), in accordance with the manufacturer's protocol. Following $6 \mathrm{~h}$ of incubation, an equal volume of fibroblast growth medium 2 (cat. no. C-23020; PromoCell, Heidelberg, Germany) was added. The cells were then used for estimating the expression of $\alpha$-SMA, fibronectin and Col-1 at $16 \mathrm{~h}$ post-transfection. The transfection efficiency was evaluated by western blot analysis of the protein expression of $\operatorname{Smad} 2 / 3$.

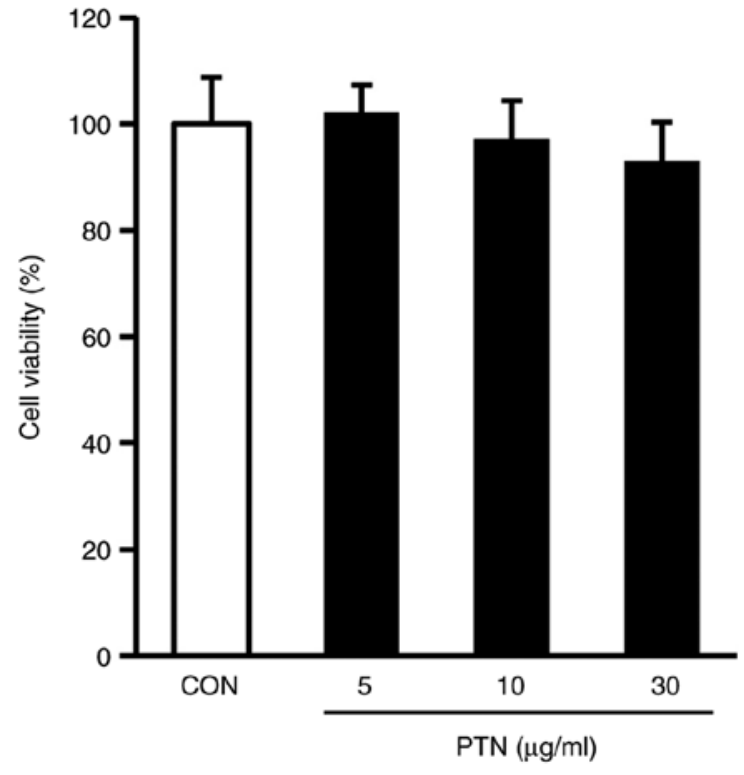

Figure 2. Effect of PTNs on NPDF viability. The cells were treated with various concentrations $(5-30 \mu \mathrm{M})$ of PTNs for $24 \mathrm{~h}$. Cell viability was assessed using the Cell Counting Kit- 8 assay, and the results are expressed as the percentage of surviving cells relative to the untreated cells. Each value indicates the mean \pm standard error of the mean and is representative of results obtained from three independent experiments. PTN, phlorotannin; CON, control.

Rat tail type-1 collagen gel contraction assay. The rat tail type-1 collagen gel contraction assay was performed as previously described (16). Briefly, type-1 collagen from the rat tail was diluted with fibroblast basal medium (CC-3131; Lonza Group, Ltd., Basel, Switzerland) to a concentration of $1 \mathrm{mg} / \mathrm{ml}$ and mixed with NPDFs to reach a final concentration of $1 \times 10^{5}$ cells $/ \mathrm{ml}$. Following the addition of $1 \mathrm{~N} \mathrm{NaOH}$ as per the manufacturer's protocol, $500 \mu \mathrm{l}$ of the cell-collagen mixture was added into each well of a 24-well cell culture plate. The plate was incubated at $37^{\circ} \mathrm{C}$ for $30 \mathrm{~min}$. The cells were then incubated in fibroblast growth medium 2 overnight, and treated with PTNs and TGF- $\beta 1$, as indicated. The gel sizes were measured using ImageJ software (version 1.51j8; National Institutes of Health, Bethesda, MD, USA).

Statistical analysis. Data are presented as the mean \pm standard error of the mean. All statistical analyses were performed with GraphPad Prism software 5.0 (GraphPad Software Inc., La Jolla, CA, USA). Comparisons between groups were performed by Dunnett's multiple range tests. $\mathrm{P}<0.05$ was considered to indicate a statistically significant difference.

\section{Results}

Expression of Col-1 and fibronectin in NP tissues. To examine whether Col-1 and fibronectin were expressed in NP tissues, immunohistochemistry was performed in IT tissues and NP tissues. In the NP tissues, Col-1 and fibronectin immunoreactivity was detected in lesions in which overall stroma was observed (Fig. 1A). In addition, Col-1 and fibronectin proteins were found to be expressed in the NP tissue lysates via western blot analysis (Fig. 1B). However, minimal expression signals of the Col-1 and fibronectin proteins were detected in the IT tissues. 

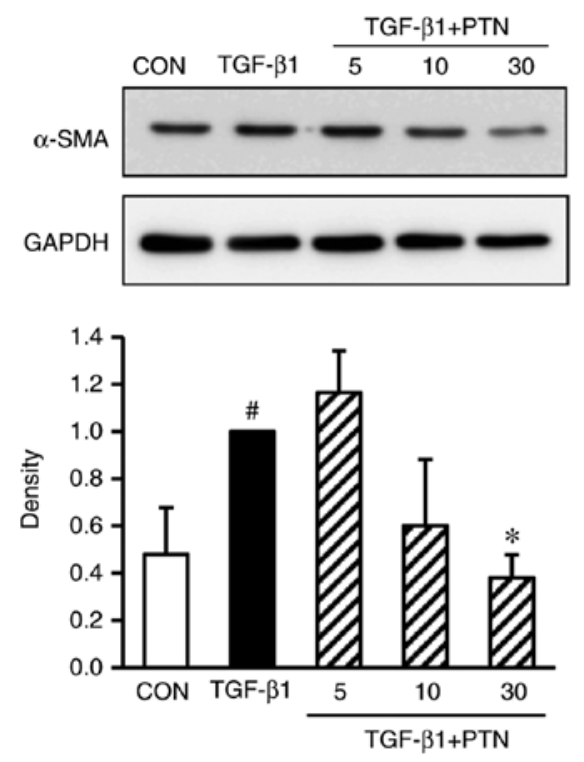
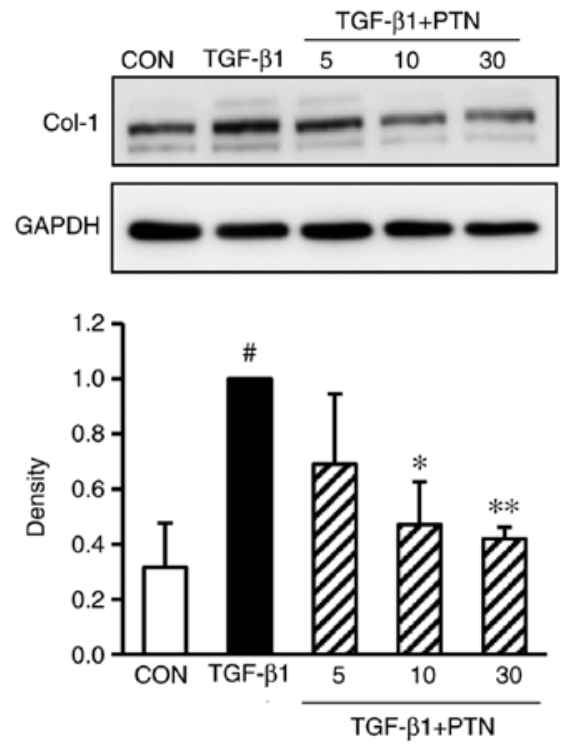
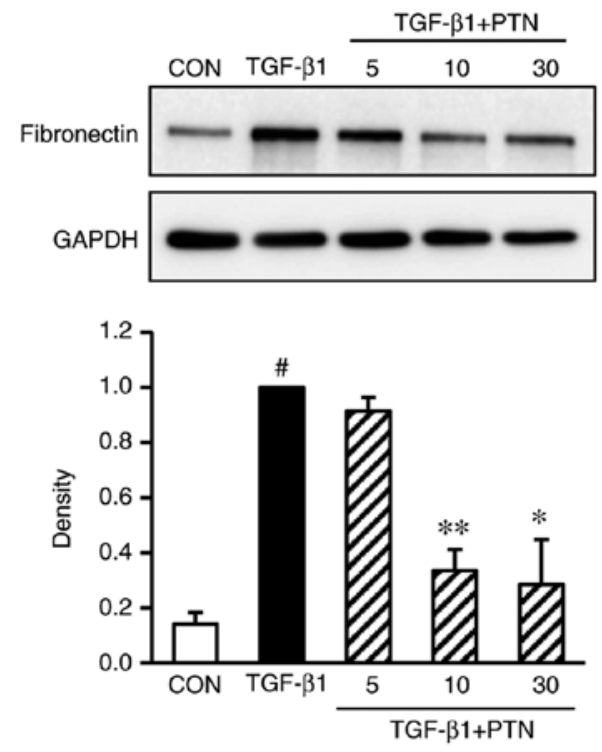

Figure 3. Effect of PTNs on protein expression levels of $\alpha$-SMA, Col-1 and fibronectin in TGF- $\beta 1$-stimulated nasal polyp-derived fibroblasts. The cells were seeded at $2 \times 10^{5}$ cells $/ \mathrm{ml}$ and incubated with various concentrations $(5,10$, and $30 \mu \mathrm{M})$ of PTNs for $1 \mathrm{~h}$ prior to TGF- $\beta 1 \mathrm{stimulation}(1 \mathrm{ng} / \mathrm{ml})$. Following stimulation with TGF- $\beta 1$ for $3 \mathrm{~h}$, and the protein expression of $\alpha$-SMA, Col-1 and fibronectin was determined by western blot analysis. GAPDH was used as an internal control. Each value indicates the mean \pm standard error of the mean, and is representative of results obtained from three independent experiments. ${ }^{\#} \mathrm{P}<0.05$, vs. CON group (no treatment); ${ }^{*} \mathrm{P}<0.05$ and ${ }^{* *} \mathrm{P}<0.01$ vs. TGF- $\beta 1$ group. PTN, phlorotannin; TGF- $\beta 1$, transforming growth factor- $\beta 1 ; \alpha$-SMA, $\alpha$-smooth muscle actin; Col-1, collagen type-1; CON, control.

Effects of PTNs on the viability of NPDFs. The viability of the NPDFs treated with PTNs was examined using the CCK- 8 assay. There was no cytotoxicity towards NPDFs at PTN doses up to $30 \mu \mathrm{g} / \mathrm{ml}$ (Fig. 2). On the basis of these results, a PTN concentration range of $5-30 \mu \mathrm{g} / \mathrm{ml}$ was selected for the subsequent experiments.

Effect of PTNs on protein expression levels of $\alpha$-SMA, Col-1, and fibronectin in TGF- $\beta 1$-induced NPDFs. To determine whether PTNs attenuated the TGF- $\beta 1$-induced expression of $\alpha$-SMA, Col- 1 and fibronectin in TGF- $\beta 1$-stimulated NPDFs, the cells were treated with various concentrations of PTNs (5-30 $\mu \mathrm{g} / \mathrm{ml}$ ) for $30 \mathrm{~min}$, prior to TGF- $\beta 1$ stimulation for $24 \mathrm{~h}$. It was found that the expression levels of $\alpha$-SMA, Col- 1 and fibronectin were significantly attenuated in a PTN concentration-dependent manner (Fig. 3).
PTNs inhibits TGF- $\beta 1$-stimulated Smad2/3 signaling pathways. The phosphorylation of Smad2 and Smad3 in NPDFs was markedly enhanced by TGF- $\beta 1$ induction (Fig. 4A). However, when the cells were pretreated for $30 \mathrm{~min}$ with PTNs, particularly at $30 \mu \mathrm{g} / \mathrm{ml}$, prior to TGF- $\beta 1$ stimulation for $24 \mathrm{~h}$, the phosphorylation of Smad 2 and $\mathrm{Smad} 3$ was significantly reduced. Therefore, the antifibrotic effects of PTNs may be mediated by the inhibition of TGF- $\beta 1$-induced Smad2/3 signaling pathways.

Silencing of Smad2/3 inhibits the TGF- $\beta 1$-induced expression of $\alpha-S M A$, Col-1 and fibronectin in NPDFs. To confirm whether Smad $2 / 3$ are critical to the TGF- $\beta 1$-induced expression of $\alpha$-SMA, Col- 1 and fibronectin in TGF- $\beta 1$-stimulated NPDFs, siRNAs were used to knock down the Smad2/3 genes in the NPDFs, and the expression levels of $\alpha$-SMA, Col-1 and fibronectin were examined. As expected, the siRNA-mediated 
A
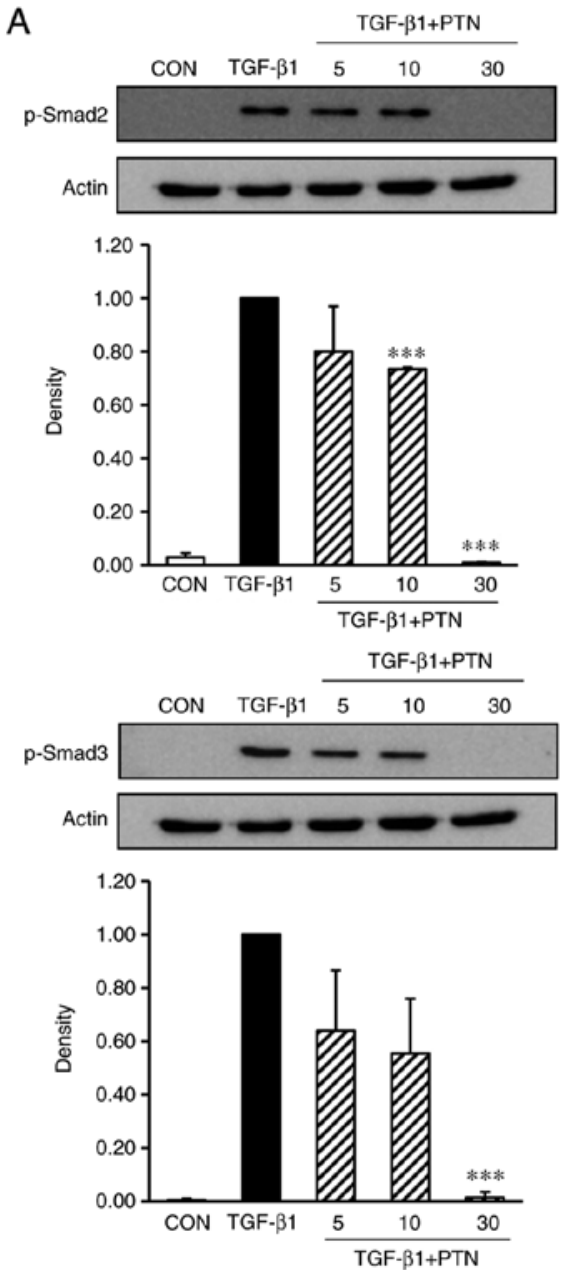

B
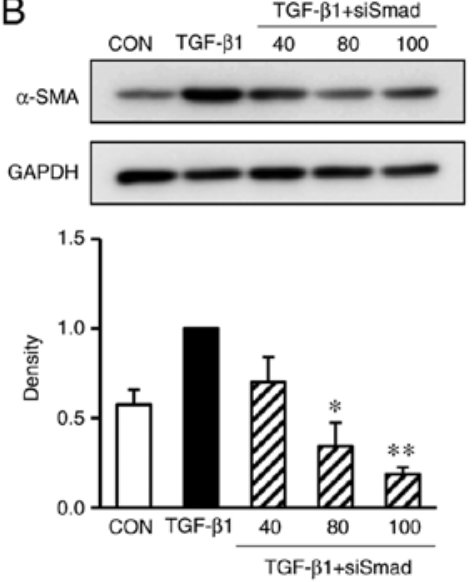
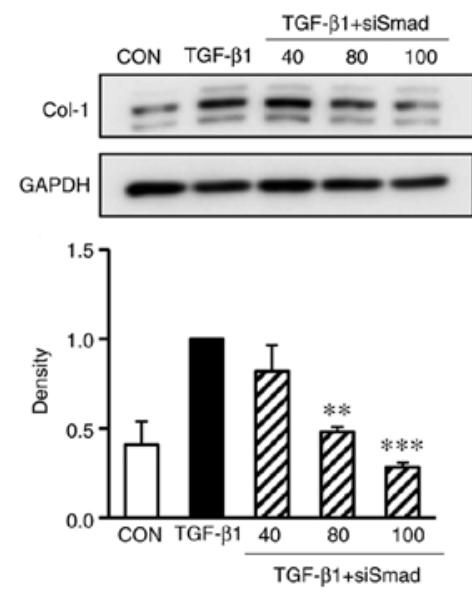
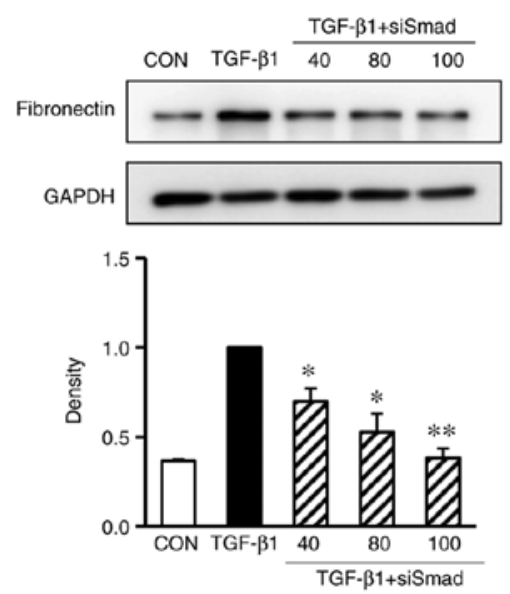

Figure 4. Effect of PTNs on Smad2/3 activation in TGF- 31 -stimulated NPDFs. (A) NPDFs were treated with either the vehicle or the indicated concentrations of PTNs $(5-30 \mu \mathrm{M})$ for $30 \mathrm{~min}$, prior to stimulation with TGF- $\beta 1(1 \mathrm{ng} / \mathrm{ml})$ for $30 \mathrm{~min}$. Nuclear protein extracts were then prepared and subjected to western blot analysis with antibodies specific for p-Smad 2 and p-Smad3. The results presented are representative of three independent experiments. (B) Smad2/3-silencing inhibited the protein expression of $\alpha$-SMA, Col-1 and fibronectin in TGF- $\beta 1$-stimulated NPDFs. The NPDFs were transfected with the indicated concentrations of siSmad2/3 (40, 80, and $100 \mathrm{nM})$ for $24 \mathrm{~h}$, prior to stimulation with TGF- $\beta 1(1 \mathrm{ng} / \mathrm{ml})$ for $24 \mathrm{~h}$. Each bar represents the mean \pm standard error of the mean from three independent experiments. ${ }^{*} \mathrm{P}<0.05,{ }^{* *} \mathrm{P}<0.01$ and ${ }^{* * *} \mathrm{P}<0.001$ vs. TGF- $\beta 1$ group. NAPDFs, nasal polyp-derived fibroblasts; $\mathrm{PTN}$, phlorotannin; TGF- $\beta 1$, transforming growth factor- $\beta 1$; Smad, small mothers against decapentaplegic; p-Smad, phosphorylated Smad; $\alpha$-SMA, $\alpha$-smooth muscle actin; Col-1, collagen type-1; siSmad: Smad2/3 small interfering RNA; CON, control.

silencing of $\mathrm{Smad} 2 / 3$ resulted in significantly reduced the expression levels of $\alpha$-SMA, Col-1 and fibronectin (Fig. 4B).

PTNs inhibits TGF- $\beta 1$-induced fibroblast contractile activity. The cells were cultured in type-1 collagen gel, as described above. The cells were then pretreated with PTNs $(5,10$ or $30 \mu \mathrm{g} / \mathrm{ml})$ for $30 \mathrm{~min}$, followed by TGF- $\beta 1(1 \mathrm{ng} / \mathrm{ml})$ stimulation for $24 \mathrm{~h}$. Stimulation with TGF- $\beta 1$ resulted in a decrease in the size of the collagen gel $(73.71 \%$ vs. TGF- $\beta 1$-untreated group; $\mathrm{P}<0.05)$, whereas pretreatment with the PTNs was observed to inhibit this contraction effect at PTN concentrations of 5,10 and $30 \mu \mathrm{g} / \mathrm{ml}(100.86,106.90$ and $156.46 \%$ vs. TGF- $\beta 1$-untreated group, respectively), as shown in Fig. 5 $(\mathrm{P}<0.05$ and $\mathrm{P}<0.001)$.

\section{Discussion}

The present study investigated the antifibrotic effect and signaling mechanisms involved in the regulation by PTNs, which are well known anti-inflammatory agents. Accumulating evidence suggests that PTNs have a protective effect against inflammatory diseases $(17,18)$. NPs are associated with chronic inflammation and are characterized by structural abnormalities, including stromal fibrosis in the sinus, that cause them grow. Therefore, inhibition of the inflammatory process and attenuation of the fibrotic process is considered to be a promising strategy for the therapy of NPs.

The present study investigated the association between the morbidity and expression levels of ECM proteins in the NPs, using immunohistochemical and western blot assays. As shown in Fig. 1, the expression levels of Col-1 and fibronectin were higher in the NP tissues and lysates than those in the IT tissues used as a control. Therefore, the high expression levels of Col-1 and fibronectin were correlated with the morbidity of NPs. On the basis of this result, the antifibrogenic effect and inhibitory signaling mechanism in vitro were investigated using PTNs in TGF- $\beta 1$-induced NPDFs.

Although diverse factors have been implicated in the development and progression of fibrosis, TGF- $\beta$, one of the most potent fibrogenic factors, is considered to be crucial in the pathogenesis 
TGF- $\beta 1+$ PTN

CON

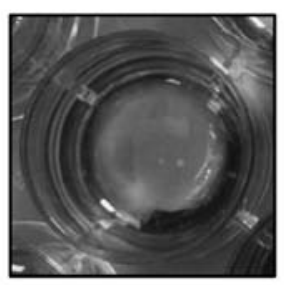

TGF- $\beta 1$

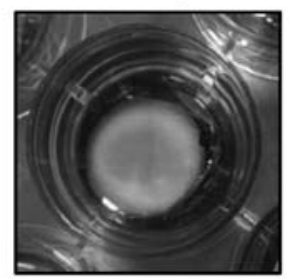

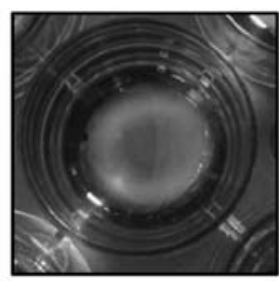

10

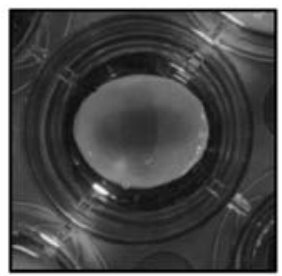

30

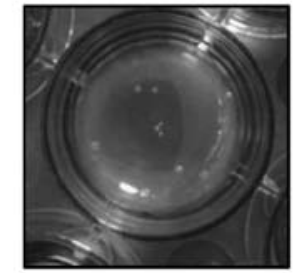

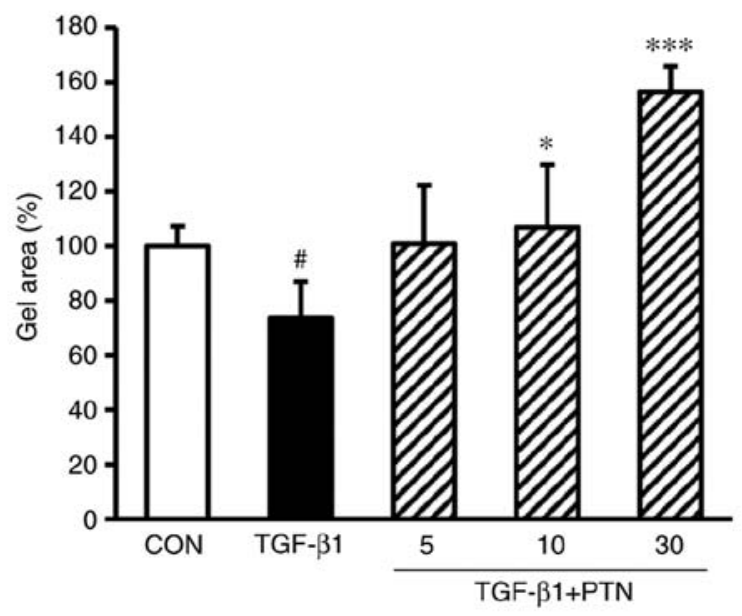

Figure 5. Effect of PTNs on the contractile activity of NPDFs in rat tail type I collagen gel. NPDFs were cultured on rat tail type I collagen gels (1 mg/ml) and pretreated with PTNs for $30 \mathrm{~min}$. Cells were exposed to TGF- $\beta 1(1 \mathrm{ng} / \mathrm{ml})$ for another $24 \mathrm{~h}$. TGF- $\beta 1$ stimulation decreased the size of the gel, whereas PTN pretreatment inhibited this reduction in gel size. The percentage of gel surface area in each well was compared with the control gel surface area. Each bar represents the mean \pm standard error of the mean from three independent experiments. ${ }^{\#} \mathrm{P}<0.05$ vs. CON group (no treatment); ${ }^{*} \mathrm{P}<0.05$ and ${ }^{* * * *} \mathrm{P}<0.001 \mathrm{vs}$. TGF- $\beta 1$ group. NAPDFs, nasal polyp-derived fibroblasts; PTN, phlorotannin; TGF- $\beta 1$, transforming growth factor- $\beta 1$; CON, control.

of fibrosis. TGF- $\beta$ is a secreted homodimeric protein that regulates multiple biological processes, including cell proliferation, differentiation, migration, extracellular matrix production, angiogenesis and apoptosis $(19,20)$. The excessive elevation of TGF- $\beta$ correlates with diverse fibrotic disorders, including pulmonary fibrosis, cardiac fibrosis, cirrhosis, glomerulosclerosis, diabetic nephropathy, Crohn's disease, rheumatoid arthritis, radiation-induced fibrosis and myocarditis in various human organs (21). Enhanced TGF- $\beta$ levels have been observed in NPs, suggesting that TGF- $\beta$ is also involved in the pathogenesis of NPs $(22,23)$ It is well known that TGF- $\beta$ induces fibroblast activation, proliferation and differentiation. Fibroblasts are found in the stroma of NPs and are considered to be important in development of fibrosis. Previous investigations on the fibroblasts of NPs showed that exposure of TGF- $\beta 1$ stimulated myofibroblast differentiation, induced collagen production and increased $\alpha$-SMA $(24,25)$. To elucidate the antifibrotic activity of PTNs, the present study investigated myofibroblast differentiation and profibrotic protein expression, in addition to the mechanism underlying the effect of PTNs in TGF- $\beta 1$-stimulated NPDFs.

Fibroblasts can be activated by various chemical signals, which promote their proliferation and differentiation into myofibroblasts (7). Myofibroblasts are characterized by their morphology, functional properties and gene expression. They are the principal effector cells, which synthesize profibrotic proteins, including $\alpha$-SMA, and high quantities of ECM proteins, particularly Col-1 and fibronectin. Myofibroblasts are important in ECM remodeling in several pathological conditions of the human airway, including asthma, chronic rhinosinusitis and NPs (26). In NPs, myofibroblasts are considered to originate via the differentiation of resident NP fibroblasts. The expression of $\alpha$-SMA is the hallmark of myofibroblast differentiation and is critical for its function. Fibronectin, a multifunctional glycoprotein involved in tissue remodeling, is known to be a chemoattractant for fibroblasts and can be released in increased quantities by the fibroblasts in response to various cytokines (27). Compared with that in the normal control IT tissues, Col-1 was found to be increased in all NPs. Collagen deposition was most abundant in the sub-mucosal connective tissue and in the basement membrane zone (28). TGF- $\beta 1$ induces fibroblast-to-myofibroblast differentiation, and increases the expression of $\alpha$-SMA, Col-1 and fibronectin. Therefore, the approaches to reduce the conversion of fibroblasts to myofibroblasts and ECM proteins may be beneficial therapeutic strategies for NPs. In the present study, it was found that the expression levels of $\alpha$-SMA, fibronectin and Col-1 were significantly induced in TGF- $\beta 1$-stimulated NPDFs. However, the results showed that PTNs inhibited the expression of $\alpha$-SMA, fibronectin and Col- 1 in response to TGF- $\beta 1$ in the absence of cytotoxic concentrations. These results suggested that PTNs suppressed TGF- $\beta 1$-induced myofibroblast differentiation and ECM protein accumulation in NPDFs.

The present study also investigated the signal pathways underlying the inhibition of $\alpha$-SMA and ECM levels by PTN treatment. TGF- $\beta$ is recognized by two heterodimeric membrane receptors, type- 1 and type-II TGF- $\beta$ receptors, which are transmembrane serine/threonine kinases (29). The Smad-dependent signal transduction system is necessary for 
TGF- $\beta$ signaling, and the TGF- $\beta /$ Smad signaling pathway is one of the most common pathways in fibrosis. When TGF- $\beta 1$ binds to its receptor, Smad2/3 is phosphorylated and binds with Smad4, consequently translocating to the nucleus, where these complexes activate the transcription of profibrotic genes and induce fibrogenesis (30). In the present study, PTN treatment was observed to attenuate TGF- $\beta 1$-induced Smad 2 and Smad3 phosphorylation in the nucleus (Fig. 4A). To further confirm the role of $\mathrm{Smad} 2 / 3$ in the inhibitory effect of PTNs, siRNAs were used to knock down the Smad2/3 genes prior to TGF- $\beta 1$ treatment in NPDFs; the levels of $\alpha$-SMA, Col-1 and fibronectin were then measured. As expected, the siRNA-mediated silencing of Smad2/3 resulted in significant inhibition of the production of TGF- $\beta 1$-induced $\alpha$-SMA and ECM proteins (Fig. 4B). These data demonstrated that PTNs inhibited myofibroblast differentiation and ECM protein accumulation by inhibiting the phosphorylation of $\mathrm{Smad} 2 / 3$ pathways in TGF- $\beta 1$-stimulated NPDFs.

Finally, the present study assessed the effect of PTN treatment on type-1 collagen gel contraction mediated by TGF- $\beta 1$-stimulated NPDFs. Myofibroblasts have increased contractile activity owing to their elevated expression levels of $\alpha$-SMA with increasing mechanical load (31). Simulation with TGF- $\beta 1$ resulted in a decrease in the size of the collagen gel, indicating an increase in contractility, whereas pretreatment with PTNs was observed to inhibit the collagen gel contraction (Fig. 5). Collectively, these results confirmed that PTNs suppressed the TGF- $\beta 1$-mediated fibrotic process in vitro.

In conclusion, the results of the present study demonstrated that PTNs effectively suppressed TGF- $\beta 1$-augmented myofibroblast differentiation, ECM protein accumulation, and collagen gel contraction in vitro, by inhibiting the phosphorylation of Smad2/3 signaling pathways in NPDFs. These results suggested that PTNs may be potential therapeutic agents for treating NP formation. Furthermore, this possibility has important implications in the development of novel therapeutic approaches for managing any fibrotic disorder in the future.

\section{Acknowledgements}

Not applicable.

\section{Funding}

This study was supported by the National Marine Biodiversity Institute of Korea Research program (grant no. 2018M00700).

\section{Availability of data and materials}

The datasets used and/or analyzed during the current study are available from the corresponding author on reasonable request.

\section{Authors' contributions}

JP, GC, DL and IC conceived and designed the project and prepared the manuscript. MY, JL, JY, WP and TK performed the experiments. SeP and SS performed statistical analysis and data interpretation. SaP, DL and IC analyzed the data. DL and IC wrote the manuscript. All authors have read and approved the final manuscript.

\section{Ethics approval and consent to participate}

The study was approved by the Local Ethics Committee of Busan Paik Hospital, Inje University.

\section{Patient consent for publication}

Not applicable.

\section{Competing interests}

The authors declare that they have no competing interests.

\section{References}

1. Cho JS, Kang JH, Shin JM, Park IH and Lee HM: Inhibitory effect of delphinidin on extracellular matrix production via the MAPK/NF- $\kappa$ B pathway in nasal polyp-derived fibroblasts. Allergy Asthma Immunol Res 7: 276-282, 2015.

2. Pawankar R: Nasal polyposis: An update: Editorial review. Curr Opin Allergy Clin Immunol 3: 1-6, 2003.

3. Jung JW, Park IH, Cho JS and Lee HM: Naringenin inhibits extracellular matrix production via extracellular signal-regulated kinase pathways in nasal polyp-derived fibroblasts. Phytother Res 27: 463-467, 2013.

4. Cho JS, Moon YM, Um JY, Moon JH, Park IH and Lee HM: Inhibitory effect of ginsenoside $\mathrm{Rg} 1$ on extracellular matrix production via extracellular signal-regulated protein kinase/activator protein 1 pathway in nasal polyp-derived fibroblasts. Exp Biol Med (Maywood) 237: 663-669, 2012.

5. Kondo S, Kagami S, Urushihara M, Kitamura A, Shimizu M, Strutz F, Müller GA and Kuroda Y: Transforming growth factor-betal stimulates collagen matrix remodeling through increased adhesive and contractive potential by human renal fibroblasts. Biochim Biophys Acta 1693: 91-100, 2004.

6. Nakagawa T, Yamane H, Nakai Y, Shigeta T, Takashima T and Takeda Z: Comparative assessment of cell proliferation and accumulation of extracellular matrix in nasal polyps. Acta Otolaryngol Suppl 538: 205-208, 1998.

7. Kendall RT and Feghali-Bostwick CA: Fibroblasts in fibrosis: Novel roles and mediators. Front Pharmacol 5: 123, 2014.

8. Suleria HA, Osborne S, Masci P and Gobe G: Marine-based nutraceuticals: An innovative trend in the food and supplement industries. Mar Drugs 13: 6336-6351, 2015.

9. Lee JC, Hou MF, Huang HW, Chang FR, Yeh CC, Tang JY and Chang HW: Marine algal natural products with anti-oxidative, anti-inflammatory, and anti-cancer properties. Cancer Cell Int 13: 55, 2013.

10. Wijesinghe WA and Jeon YJ: Exploiting biological activities of brown seaweed Ecklonia cava for potential industrial applications: A review. Int J Food Sci Nutr 63: 225-235, 2012.

11. Sekar D and Kolanjinathan K: Antibacterial activity of marine macroalgae Padina gymnospora and Turbinaria conoides collected from Mandapam Coast of Tamilnadu, India. Int J Adv Res Biol Sci 2: 146-152, 2015.

12. Kolanjinathan K, Ganesh P and Saranraj P: Pharmacological importance of seaweeds: A Review. World J Fish and Marine Sci 6: 1-15, 2014.

13. Wijesekara I and Kim SK: Angiotensin-I-converting enzyme (ACE) inhibitors from marine resources: Prospects in the pharmaceutical industry. Mar Drugs 8: 1080-1093, 2010.

14. Eom SH, Kim YM and Kim SK: Antimicrobial effect of phlorotannins from marine brown algae. Food Chem Toxicol 50: 3251-3255, 2012.

15. Vo TS, Ngo DH and Kim SK: Marine algae as a potential pharmaceutical source for anti-allergic therapeutics. Process Biochem 47: 386-394, 2012.

16. Lee DS, Lee CM, Park SK, Yim MJ, Lee JM, Choi G, Yoo JS, Jung WK, Park S, Seo SK, et al: Anti-inhibitory potential of an ethanolic extract of Distromium decumbens on pro-inflammatory cytokine production in Pseudomonas aeruginosa lipopolysaccharide-stimulated nasal polyp-derived fibroblasts. Int J Mol Med 40: 1950-1956, 2017. 
17. Jung HA, Jin SE, Ahn BR,LeeCMand Choi JS: Anti-inflammatory activity of edible brown alga Eisenia bicyclis and its constituents fucosterol and phlorotannins in LPS-stimulated RAW264.7 macrophages. Food Chem Toxicol 59: 199-206, 2013.

18. Yang YI, Woo JH, Seo YJ, Lee KT, Lim Y and Choi JH: Protective effect of brown alga phlorotannins against hyper-inflammatory responses in lipopolysaccharide-induced sepsis models. J Agric Food Chem 64: 570-578, 2016.

19. Massagué J, Blain SW and Lo RS: TGFbeta signaling in growth control, cancer, and heritable disorders. Cell 103: 295-309, 2000

20. Li S, Gu X and Yi S: The regulatory effects of transforming growth factor- $\beta$ on nerve regeneration. Cell Transplant 26: 381-394. 2017

21. Pohlers D, Brenmoehl J, Löffler I, Müller CK, Leipner C, Schultze-Mosgau S, Stallmach A, Kinne RW and Wolf G: TGF-beta and fibrosis in different organs - molecular pathway imprints. Biochim Biophys Acta 1792: 746-756, 2009.

22. Chang CH, Chai CY, Ho KY, Kuo WR, Tai CF, Lin CS, Tsai SM, Wu SC and Juan KH: Expression of transforming growth factor-beta 1 and alpha-smooth muscle actin of myofibroblast in the pathogenesis of nasal polyps. Kaohsiung J Med Sci 17: 133-138, 2001.

23. Coste A, Lefaucheur JP, Wang QP, Lesprit E, Poron F, Peynegre R and Escudier E: Expression of the transforming growth factor beta isoforms in inflammatory cells of nasal polyps. Arch Otolaryngol Head Neck Surg 124: 1361-1366, 1998.

24. Shin JM, Park JH, Park IH and Lee HM: Pirfenidone inhibits transforming growth factor $\beta 1$-induced extracellular matrix production in nasal polyp-derived fibroblasts. Am J Rhinol Allergy 29: 408-413, 2015.
25. Shin JM, Park JH, Park IH and Lee HM: Doxycycline inhibits TGF- $\beta 1$-induced extracellular matrix production in nasal polyp-derived fibroblasts. Int Forum Allergy Rhinol 6: 256-263, 2016.

26. Park SK, Jin YD, Park YK, Yeon SH, Xu J, Han RN, Rha KS and Kim YM: IL-25-induced activation of nasal fibroblast and its association with the remodeling of chronic rhinosinusitis with nasal polyposis. PLoS One 12: e0181806, 2017.

27. Sugiura H, Ichikawa T, Liu X, Kobayashi T, Wang XQ, KawasakiS, Togo S, Kamio K, Mao L, Ann Y, et al: N-acetyl-L-cysteine inhibits TGF- $\beta 1$-induced profibrotic responses in fibroblasts. Pulm Pharmacol Ther 22: 487-491, 2009.

28. Molet SM, Hamid QA and Hamilos DL: IL-11 and IL-17 expression in nasal polyps: Relationship to collagen deposition and suppression by intranasal fluticasone propionate. Laryngoscope 113: 1803-1812, 2003.

29. Ahn JY, Kim MH, Lim MJ, Park S, Lee SL, Yun YS and Song JY: The inhibitory effect of ginsan on TGF- $\beta$ mediated fibrotic process. J Cell Physiol 226: 1241-1247, 2011.

30. Zhou L, Dong X, Wang L, Shan L, Li T, Xu W, Ding Y, Lai M, Lin X, Dai M, et al: Casticin attenuates liver fibrosis and hepatic stellate cell activation by blocking TGF- $\beta /$ Smad signaling pathway. Oncotarget 8: 56267-56280, 2017.

31. Wipff PJ, Rifkin DB, Meister JJ and Hinz B: Myofibroblast contraction activates latent TGF-betal from the extracellular matrix. J Cell Biol 179: 1311-1323, 2007. 